\title{
ESTUDIOS
}

\section{Las canciones patrióticas de José Bernardo Alzedo (1788-1878)}

\author{
The Patriotic Songs of José Bernardo Alzedo \\ (1788-1878)
}

\author{
por \\ Víctor Rondón \\ Facultad de Artes, Universidad de Chile, Chile \\ rondon.victor@gmail.com
}

\author{
José Manuel Izquierdo König \\ Gates Cambridge Scholar, University of Cambridge, Inglaterra \\ izquierdokonig@gmail.com
}

José Bernardo Alzedo, compositor peruano nacido en Lima, es principalmente recordado por ser autor del Himno Nacional del Perú. Sin embargo, esta marcha cuyo texto comienza con las palabras "Somos libres" forma parte de una serie de canciones patrióticas creadas para distintas ocasiones y espacios sociales. Si bien se han conservado solo cuatro de estas canciones, ellas alcanzan a evidenciar cómo Alzedo utilizó diversos recursos y propuestas musicales para comunicar el ideal libertario con el que comulgaba. Esto, en la compleja situación política del país en general a comienzos del siglo XIX y la no menos peculiar situación de él mismo como individuo religioso dominico, en ese momento. Este ensayo propone que la canción patriótica, vista como género mediante la producción de este compositor, fue un medio dúctil y eficaz para expresar distintas posturas ideológicas y estéticas en diversos espacios públicos y privados de la sociedad limeña en la primera mitad de la década de 1820 .

Palabras clave: música, Perú, canción patriótica, himno nacional, Alzedo.

José Bernardo Alzedo, a Peruvian composer born in Lima in 1789, is mostly remembered as the author of the music of the Peruvian National Anthem. Nevertheless, this famous march generally known by the initial words of the text - "Somos libres"- was written as part of a series of patriotic songs created by the composer for a variety of social occasions and settings. Only four of them have survived, but they clearly show how Alzedo used an impressive array of different musical resources to communicate his own ideals for the independence of his country. This was done within the complex political situation of Peru at the beginning of the 19th century, and the peculiar situation of Alzedo himself as a Dominican friar in Lima. The point of this article is that the patriotic song, considered as a genre within Alzedo's output during these years, was a malleable and effective means to express different ideological and aesthetic positions in various private and public settings of the society and context of Lima in the first half of the 1820's.

Key words: music, Peru, patriotic song, national anthem, Alzedo.

\section{INTRODUCCIÓN}

Las primeras décadas del siglo XIX se vivieron en América Latina como parte de un proceso de crisis que en menos de medio siglo llevó al descalabro generalizado 
del imperio ibérico en el continente. Frente a esta situación, cada ciudadano, antes súbdito leal al rey, tuvo que reinventarse tanto en su participación frente a los esquemas sociales que le eran contemporáneos como también al modo específico en que contribuiría al nuevo orden social, aun cuando este estuviese inevitablemente conectado al pasado.

El caso de José Bernardo Alzedo (1788 - 1878) aparece como de particular interés en este contexto debido a su situación personal y relevancia como personaje público de autor musical del Himno Nacional del Perú. El presente trabajo intenta demostrar que dicho himno es, en realidad, parte de un conjunto más amplio de piezas de diversa temática creadas con fines patrióticos para diferentes espacios. Tales composiciones, a su vez, remiten a los modelos melódicos, armónicos y retóricos que circulaban en Lima a comienzos del período decimonónico en espacios seculares, aunque creadas por un compositor cuya realidad hasta entonces se había concentrado de manera prioritaria en aquella música que circulaba en espacios religiosos.

El trabajo de Alzedo, desde sus comienzos como estudiante hasta el final de su larga carrera, es una muestra concreta de su capacidad para adoptar diversos estilos, modelos e influencias y, por lo tanto, jugó un rol activo en la actividad musical de su tiempo. Por esto, su figura es de especial riqueza para un ejercicio comprensivo de una trayectoria vital en relación con la creación de un repertorio, en este caso, el de las canciones patrióticas peruanas de comienzos del siglo XIX.

La catalogación en proceso de su música, así como una revisión más detenida de sus composiciones creadas antes del abandono del claustro dominico en $1822^{1}$, nos ha permitido considerar estas canciones patrióticas como parte de un proceso más amplio. En resonancia con lecturas históricas actuales acerca del quiebre independentista y la década de $1820,{ }^{2}$ ha permitido además visualizar lo que en ellas existe tanto de nuevo y local como de herencia del pasado de influjo centroeuropeo.

1 El presente artículo es producto del proyecto "El músico pardo J. B. Alzedo como clave interpretativa histórico-musicológica de transiciones múltiples: colonia-república, religioso-civil, peruano-chileno, pardo-blanco" (Fondecyt No 1120104, 2012-2014). Comprendió trabajos de investigación tanto en Santiago como en Lima. En esta última capital, la Biblioteca Nacional del Perú, a instancias del Ministerio de Cultura, nos propuso reunir en formato digital toda la producción de Alzedo en una colección especial, proveniente de instituciones chilenas y peruanas. Este objetivo se materializó en una ceremonia celebrada el 25 de julio de 2013. Agradecemos al músico peruano Armando Sánchez Málaga, quien en su calidad de asesor del entonces ministro de Cultura del Perú, el doctor Luis Peirano, logró que el gobierno apoyara esta feliz idea. A partir de este corpus, que por primera vez reunía la obra de Alzedo, hemos comenzado la catalogación de su obra, la transcripción de sus obras más relevantes, y el análisis y caracterización de sus períodos creativos, labor aún en progreso. La Orden de Predicadores de Santo Domingo por medio de su provincia de San Juan Bautista, del Perú, con asiento en el convento del Santo Rosario de Lima, y el Instituto Dominicano de Investigaciones Históricas, con sede en Querétaro, México, han colaborado con generosidad en esta tarea, al igual que en Chile lo han hecho la Catedral de Santiago, la Biblioteca Patrimonial de la Recoleta Dominica (administrada por la Dirección de Bibliotecas, Archivos y Museos [Dibam]) y el Seminario Pontificio Mayor de Los Santos Ángeles Custodios, quienes nos han permitido el acceso a las partituras de Alzedo custodiadas en sus respectivos archivos musicales.

2 Ver, por ejemplo, Brown y Paquette 2011: 387-396 y Brown y Paquette 2013. 
Aunque el elemento patriótico militar estará también presente en la obra de Alzedo en años posteriores, tanto en su música religiosa a fines de la década de 1840 como en las canciones realizadas en tiempos de la tardía guerra con España hacia 1866, tal etapa creativa no será abordada en este trabajo. Nos concentraremos en las cuatro canciones que han sobrevivido: ${ }^{3}$ Somos libres, actual Himno Nacional del Perú, La Cora, La chich a y La despedida de las chilenas al Ejército de San Martín Libertador del Perú. El objetivo es establecer tanto sus relaciones múltiples con el contexto limeño de 1821 y el período inmediatamente anterior, como también relacionar entre sí las características particulares de cada una de estas composiciones.

Existen referencias a estas canciones en diversas publicaciones, porque fueron mencionadas en la biografía de Alzedo escrita por Coronel Zerraga como prólogo de su Filosofía elemental de la música ${ }^{4}$. No obstante, la escasez de estudios y análisis basados en la consulta directa de ellas no ha permitido un avance sustantivo sobre el conocimiento de sus características. Juan Carlos Estenssoro, en su texto sobre la música en el Perú, las considera como canciones propias de la tonadilla escénica con tema peruano desarrolladas entre 1810 y 1830, caracterizando incluso a $L a$ chich a como un "yaraví teatral imitando el canto en terceras que posee el género popular"5. Creemos, sin embargo, que no existen fuentes suficientes como para establecer un punto de comparación con otras canciones teatrales y determinar con certeza su rol genérico, ya que, por ejemplo, el canto en terceras paralelas es también común en otras formas de canción popular y no solo del yaraví ${ }^{\text {. No }}$ obstante, sabemos que el himno Somos libres se estrenó en un escenario teatral en 1821 y no podemos descartar que otras lo hayan hecho del mismo modo, como lo detallaremos más adelante, debido a la relevancia del espacio teatral para la comunicación de ideas durante los últimos años coloniales y los primeros republicanos. Del mismo modo, sabemos que Rosa Merino cantó La chicha en el teatro limeño en 1822, aunque su voz apenas se podía oír "por el incesante palmoteo de los circunstantes"7. Pero tal como en el caso del himno, el hecho de haber sido

3 Otra dos canciones son La Pola y la Burla a las godas, que no hemos ubicado aunque son mencionadas por Coronel Zegarra (1869: viii) y en el obituario de Alzedo, basado en las noticias del mismo autor, aparecido en El Peruano (diario oficial) del jueves 2 de enero de 1879 .

4 Este tratado, redactado en las dos últimas décadas de su estadía en Santiago de Chile y publicado de vuelta en Lima en 1869, se inicia con una especie de reseña biográfica redactada por Félix Cipriano Coronel Zegarra. Por cuanto fue escrita en vida de Alzedo, y obviamente autorizada por él, se tuvo por muchas décadas como una fuente autorizada para saber de la vida del músico. Así fueron repitiéndose tales datos hasta que diversos estudios posteriores, ya en el siglo XX, han evidenciado sus errores e inconsistencias. Tal semblanza, también, ensaya un primer resumen de su catálogo compositivo.

5 Estenssoro 1989: 58.

6 Una posibilidad para realizar este trabajo sería establecer relaciones con, por ejemplo, aquellos casos de tonadillas escénicas y arias de ópera que sí han sobrevivido de fines del siglo XVIII en la Biblioteca Nacional del Perú. Sin embargo, no conocemos ningún caso de yaraví teatral que sí haya pervivido. Aquellos ejemplos del género que sí se conocen hoy, como los de Pedro Ximénez, no parecen compartir rasgos explícitos definitorios con La chicha o La cora.

7 En el Correo Mercantil, Político y Literario, N 15, 23 de febrero de 1822. Citado por Raygada 1951, I: 37 . 
cantada en un escenario teatral no necesariamente la define como una canción teatral, debido al uso que tenía este espacio como comunicador de ideas.

\section{LA MÚSICA EN LIMA A COMIENZOS DEL SIGLO XIX}

La vida musical de Lima, en palabras del propio Alzedo, era de una bullente actividad hacia el 1800. Por una parte, según señala en su Filosofía, "se contaban en Lima doce orquestas más o menos numerosas, de buena inteligencia y mejor ejecución"8, mientras que por otra, tenemos noticias de música en salones, teatros y, en forma mayoritaria, en iglesias. Si bien buena parte de estas prácticas han sido vistas como una herencia colonial finisecular, pareciera que igual revisten un particular interés. Stevenson, por ejemplo, remite a las academias privadas, o conciertos en salones particulares con fines más de socialización que de formación musical, como aquellos de Antonio Feliciano González de la Fuente o del Marqués de Montemira, un chelista aficionado que, incluso, pudo haber tenido alguna relación con el propio Alzedo ${ }^{9}$.

Por otra parte, se constata la influencia local de varios artistas, tanto peruanos como extranjeros, en forma prioritaria ligados al aparato religioso, aunque también al Teatro de Comedias, lugar menos frecuentado por Alzedo dada su condición de religioso conventual. Entre ellos, quizás en forma preponderante, encontramos al italiano Andrés Bolognesi, en quien confluía la condición de virtuoso chelista y maestro de capilla en la Catedral de Lima, con toda probabilidad el puesto más importante para un músico dentro del Virreinato del Perú de entonces. Junto a él debe mencionarse a Melchor Tapia, organista primero de la misma catedral, al agustino Cipriano Aguilar y a Toribio José del Campo, a quienes Alzedo recordaba en su Filosofía de 1869. Si bien otros músicos ejercían un papel relevante en otras ciudades del virreinato, como es el caso de José de Campderrós en Santiago, es el círculo limeño el que aparece en perspectiva como el centro neurálgico en la creación musical de la zona a comienzos del siglo XIX. Sin duda, fueron estos músicos la influencia más directa y cercana para el joven Alzedo.

Hacia 1809 Bolognesi había planteado una serie de reformas para la capilla de la Catedral de Lima, posiblemente la agrupación musical más relevante de la ciudad, aunque no todas se llevaron a efecto. A modo de ejemplo la solicitud en ellas, de contrabajos y cornos para un mejor timbre y balance orquestal, evidencian la búsqueda de un sonido más "clásico", o centroeuropeo, algo también reflejado en su ideal de orquesta, con al menos cuatro violines y un chelo, instrumento que no se utilizaba de modo regular en este espacio ${ }^{10}$.

Si bien este sonido "clásico" de configuración europea se estaba instalando con fuerza en Lima en estas primeras décadas del siglo XIX, la tradición musical de la ciudad debió implicar que buena parte de los conjuntos siguieran la

\footnotetext{
8 Alzedo 1869: xx.

9 Stevenson 1971: 3.

10 Eyzaguirre 1973: 40-43.
} 
configuración del periodo anterior. Este también se ve reflejado en las múltiples partes orquestales de tonadillas y piezas de teatro que sobreviven en la Biblioteca Nacional de Lima, ${ }^{11}$ con un par de violines, una pareja de cornos, más algún otro viento (oboes, clarinetes, flautas) y un bajo continuo que mantenía cierta flexibilidad en la elección de su composición instrumental. Esta es, también, la configuración que aparece con claridad en las composiciones de Alzedo que, bajo diversas luces, pueden adscribirse a su período creativo en los años anteriores a la Independencia ${ }^{12}$. La relación con el teatro es de especial importancia, pues en él se desarrolló, quizás con mayor fuerza, un ideal ilustrado cuyas ideas están muchas veces presentes -aceptadas o discutidas- en la poesía de la época y en las canciones de Alzedo.

Es oportuno señalar que el proceso ilustrado se ve reflejado principalmente en las discusiones intelectuales criollas en la prensa. No obstante la educación misma en varias provincias del Virreinato del Perú se vio afectada por los nuevos ideales con bastante rapidez, aun cuando el apelativo de "ilustrado" no se utilizara del todo. ${ }^{13}$ La ilustración no llegó a América de un modo jurídico y administrativo, esto es, mediante las reformas borbónicas y sus disposiciones, sino también como una operación intelectual, reflejo local de las academias francesas y de un ideal de rebelión mental, y luego físico, en pos de la verdad ${ }^{14}$.

La idea de utilizar la música como un medio político se recoge en decenas de páginas del período como expresión central y directa de lo ilustrado. Acerca de este último concepto El Telégrafo de Lima aventuraba algunas definiciones en 1835: "Pueblo ilustrado se llamará aquel cuyos ciudadanos sean respectivamente ilustrados $[\ldots]$ que tengan en sus carreras, artes o profesiones respectivas, mayor cantidad de conocimientos"15. En tal sentido, la posibilidad de la nación para ascender en su rango de modernidad y excelencia pasaba por el nivel de educación de todos sus ciudadanos (al menos en términos ideales) en el perfeccionamiento de sus actividades y en su desarrollo como personas. Si bien desde los primeros avances coloniales el tema de la felicidad se había arraigado en el espacio religioso por medio de la fe como una proyección del modelo cristiano medieval, el teatro ilustrado, en su rol moral y educativo, apareció como un nuevo proyecto hacia el 1800 en buena parte de América, con un repertorio secular que apelaba a la razón.

El teatro, como espacio sociocultural, era considerado como el foco más relevante para la comunicación de ideales y construcción de moral e identidad pública para las nuevas naciones. De un modo transversal, cuando se remite a música y/o arte en la prensa de la época se asocia en forma genérica al teatro.

11 Por ejemplo, el aria de Ezio de Giovanni Marco Rutini (MsMu 2.1A); el final a dúo escrito en 1800 por Narciso Martínez (MsMu 7.1) o la comedia San Pedro Mártir, escrita en Lima en 1793 (MsMu 8.4).

12 Por una aproximación a la caracterización de este período temprano ver Rondón 2013.

13 Un recuento más detallado de la revolución ilustrada en América se encuentra en Guerrero 2006.

14 Alridge 1971: 8-9.

15 Citado por Loayza 2006: 52. 
Para un periódico limeño del mismo año de la independencia peruana, la música es parte central del esquema educativo de un ciudadano, pues esta, "a más de conocer el gusto del pueblo, es siempre intérprete de su carácter"16. En otras palabras, la música constituye un elemento intrínseco del modo en que un pueblo se ve reflejado culturalmente y, a la vez, de la manera en que se muestra al resto de las naciones. Poco antes, en Chile, se leía una definición aún más precisa del rol de la música y, específicamente, de qué música se trata: "La música, la poesía y el canto tiene un influjo directo sobre la organización moral de los individuos". Para el autor de dicho artículo, "Hayden y Pleyel y estos héroes del Parnaso, creando [...] la danza y la Orquesta, é imitando los acentos de la Lira de Apolo, pintaron las nobles pasiones del corazón y afearon las malas con coloridos simétricos"17.

Por tanto, el sonido de esta moralidad no está dado por cualquier música, sino por algunos autores y una estética específica, una de "coloridos simétricos" y, se entiende, de orden y disciplina. El problema exacto de cómo lograr esa realidad y cómo transmitirla era, justamente, lo que alguien como Alzedo podía resolver. En este sentido sus canciones patrióticas funcionan como un eco personal y colectivo de las aspiraciones ilustradas, utilizando la música como medio de comunicación de ideas políticas específicas en el contexto de la Lima revolucionaria a comienzos de la década de 1820.

\section{UN MÚSICO PARDO FRENTE A LAS GUERRAS DE INDEPENDENCIA}

Alzedo vivió sus primeros años de vida en medio de profundos cambios políticos y sociales en el Virreinato del Perú. La revolución de Tupac Amaru II en 1780-81 y una escalada de protestas locales, principalmente por problemas de impuestos, apuntaban ya a una intranquilidad política en las últimas décadas del siglo XVIII. Sin duda, las reformas bórbonicas habían afectado profundamente el contexto limeño, con la transferencia de enormes zonas de terreno y poderío económico al nuevo Virreinato del Río de la Plata en 1776, lo que, en la práctica, significó una rotación del poder real en América desde la costa del Pacífico a la del Atlántico. ${ }^{18}$ La apertura de los puertos en 1777 implicó además, por primera vez, un menor control de la península sobre el comercio, transferencia de bienes y creación de redes locales en América del Sur, lo que, en teoría al menos, debió haber facilitado la transmisión de conocimientos entre diversas ciudades europeas y americanas. Esto se refleja puntualmente, por ejemplo, en la radicalidad de diversos artículos de El Mercurio Peruano, aparecidos cuando Alzedo era todavía un niño, en los que la discusión por una posible peruanidad se volvió cada vez más específica. ${ }^{19}$ Es muy probable que estas ideas fueran calando hondo en su persona.

16 Los Andes Libres, Lima, N¹1, 26 de octubre de 1821. Citado por Morán 2011: 98.

17 El Argos de Chile, publicado el 3 de septiembre de 1818.

18 Más sobre las reales implicancias económicas y políticas de este "giro" geopolítico americano en Mahoney 2010.

19 Por ejemplo, el artículo del músico José Rossi y Rubí "Idea general del Perú", en El Mercurio Peruano. $\mathrm{N}^{\circ}$ 1, del 2 de enero de 1791, con su apreciación de las ventajas del país desde una mirada 
Pero Alzedo, es importante señalarlo, no era parte de la alta sociedad limeña, y ni siquiera de los círculos burgueses que progresivamente iban tomando importancia en la ciudad. Alzedo, en una sociedad marcadamente estratificada, era parte de un segmento social en el que la práctica musical era considerada parte de un oficio manual y artesanal. Como hijo de una mulata libre, en el orden colonial, Alzedo difícilmente podía pensar en un futuro fuera de este esquema. Al respecto cabe recordar aquí un documento sin fecha referido por Andrés Sas en el que se señalaba hacia 1800 que por ningún motivo podían aceptarse negros o gente mestiza en la capilla de la Catedral de Lima, sino que se buscaran indios y españoles, idealmente estos últimos o jóvenes de "buenas familias" 20.

De hecho, la revolución de Haití había generado un miedo particular a los levantamientos en todos los territorios coloniales de ultramar, no solo en América, mientras que para otros grupos esta revolución había significado una luz de esperanza confusa que se añadía a las noticias cambiantes desde Francia. A lo largo de la América Hispana, como ha señalado John Chasteen (2008), se instaló una esperanza de movilidad social para los diversos grupos pardos, particularmente en las grandes ciudades, que incluía la venta de excepciones que podían transformar a un ciudadano pardo legalmente en blanco, como en Venezuela, o el ingreso masivo a milicias y batallones, como sucedió en varias naciones sudamericanas como Argentina, Chile y Perú. El proceso de Independencia, complejo y a la par excitante para la generación de Alzedo, permitía sin duda vislumbrar nuevas posibilidades para quienes en la estructura colonial apenas tenían cabida. Después de más de una década de guerra, hombres como Alzedo o el mulato José Gil de Castro (1785-1841) podían vislumbrar nuevos espacios sociales, previamente cerrados para ellos.

Por eso, la formación musical desde la infancia (alrededor de 1800) y los votos juveniles como religioso dominico de orden tercera (1807-1808) fueron para Alzedo la mejor carta que su madre y él mismo pudieron plantearse como posibilidad para su futuro, considerando que era solo un hijo de mulata libre, cuyo padre criollo estuvo, al parecer, siempre ausente.

En el espacio conventual, al que estuvo adscrito Alzedo en estas primeras décadas del siglo diecinueve, se vivió lo que la propia historiografía dominicana reconoce como un tiempo de desestabilización y decadencia producidas por el impacto del contexto independentista en cuestiones de orden moral y temporal. Por una parte aquellos religiosos que mantenían su fidelidad a la Corona "despoblaron los conventos con su retirada"21. En cambio a los pocos que permanecieron expectantes y esperanzados de un nuevo orden político para su patria, los últimos gobiernos virreinales y los primeros independentistas esquilmaron su economía, llegando a decretar incluso el cierre de la mayoría de los conventos regulares. En el caso de los dominicos, el Convento del Rosario (tal es el nombre del convento de Santo Domingo donde vivió Alzedo hasta, aproximadamente, los treinta y tres

local. Ver también la entrada "Nación" para Perú, escrita por Marcel Vásquez Castro (2009).

20 Sas 1971: 89.

21 Álvarez 1997, II: 130. 
años) fue el único sobreviviente entre las diversas casas de religiosos y religiosas que la orden tenía en Lima.

Aun así, en la coyuntura misma alrededor de 1820, la comunidad y la superioridad dominicana estaban claramente alineadas tras el ideario libertador. Una vez más es la propia memoria histórica de la Orden la que destaca la influencia de algunos de sus miembros en la gesta emancipadora ${ }^{22}$. Uno de ellos fue fray Jerónimo Cavero, provincial de la orden entre 1820 y 1822, quien fue signatario del acta de la independencia peruana. Otro fue fray Ángel Vicente Zea, autor del opúsculo "El clamor de la justicia e Idioma de la verdad", diálogo en que "se vindica la causa de la Libertad Americana de las objeciones más comunes, que le hacen sus contrarios" 23 . En este escrito (cuya acción sucede en Santiago de Chile) un hermano patriota le argumenta a su hermana, católica y realista, que lo primero, su religión, no le obliga a mantener la creencia de que el único poder aceptable en este mundo sea la monarquía y que tal posición errada se debe a que no ha pensado "de un modo más ilustrado" 24 . En otra obra sobre el rol de los religiosos dominicos en el proceso independentista, esta vez en Argentina, su autor, también historiador de la Orden, afirma que "a la ilustración y criterio del clero no se le podía ocultar la necesidad imperiosa y lógica que reclamaba la pronta formación de una entidad nacional, libre de odiados tutelajes" 25 .

En tal contexto no es raro que los valores de la ilustración, asociados a los de la libertad, el progreso y el sentido patriótico, fueran adoptados sin mayores conflictos con su fe por el hermano Alzedo, y llevados a la expresión musical que su oficio y condición ponían a su disposición desde ese momento y hasta el final de sus días. Ha sido muy poco advertido que tanto la canción que sería el futuro himno nacional del Perú como las otras canciones patrióticas que nos ocupan, fueron compuestas y probablemente interpretadas por primera vez al interior de los claustros del convento de Santo Domingo.

\section{CUATRO CANCIONES PATRIÓTICAS}

Si bien es posible que Alzedo escribiera varias canciones patrióticas durante el período del arribo del Ejército Libertador al Perú y el posterior gobierno de San Martín ${ }^{26}$, solo algunas de estas se han preservado hasta hoy como documentos

22 Álvarez 1997, II: 150.

23 El catálogo de la BNC (Biblioteca Nacional de Chile) señala que este escrito fue impreso en Santiago de Chile en 1817 en la Imprenta del Estado; además de una reimpresión en 1821 en Lima. Álvarez (1997, II: 152) señala que fray J. Cavero habría ayudado a que su hermano de orden reimprimiera este escrito en Lima, en 1821.

24 Zea 1821: f1

25 Saldaña Retamar 1920: 4.

26 San Martín dirige sus primeras proclamas a los peruanos en noviembre de 1818 desde Chile, llega a las costas peruanas en septiembre de 1820, proclamando su independencia en julio de 1821 y declarándose su Protector. En julio de 1822 se retira del país y un año más tarde llega Simón Bolívar. Alzedo por su parte triunfa con su canción patriótica en septiembre de 1821, abandona el claustro para asumir la vida militar en agosto de 1822 y en tal condición se embarca a Chile hacia fines de 1823 , 
musicales ${ }^{27}$. Aun así, una característica que salta a la vista en las canciones que sobreviven es su variedad estilística y formal ${ }^{28}$. Mientras La chicha es claramente una canción estrófica con un enorme potencial para su difusión en forma oral y por la tradición popular, la Despedida de las chilenas es un aria, una pequeña escena que solo puede resolverse en su relación con el piano y la sentimentalidad de un solista sensible. Mientras que el Somos libres estructura claramente una forma de estrofa y coro, en forma de himno, La Cora es una canción estrófica narrativa, sin espacio para coros unísonos, sino que dependiente de la voz de un solista. Estas diferencias apuntan al rol que la música asumió durante el proceso de toma de conciencia de lo nacional en América Latina durante el siglo XIX, funcionando en múltiples espacios con roles distintos pero con intenciones similares.

Hemos señalado que otras dos canciones actualmente perdidas que pueden ser incluidas en este grupo de canciones patrióticas son La burla de las godas y La Pola. Sus nombres son todo lo que ha quedado de ellas. Al respecto solo podemos especular que la primera pudo haber sido una canción satírica que tomaba como sujeto a las damas españolas residentes en el Perú, probablemente realistas y contrarias a la independencia del país. De La Pola es posible proponer con algo más de certeza que se trataba de una canción que exaltaba probablemente la figura de la joven heroína libertaria colombiana Policarpia Salavarrieta Ríos ( ca. 17951817), alias "La Pola", fusilada durante la reconquista española en noviembre de 1817. Cómo fue que su figura alcanzó el ideario patriótico de Alzedo y el reconocimiento popular en la época es una cuestión que excede nuestros propósitos en este escrito. Seguramente fue un proceso rápido y extendido considerando que esta canción fue compuesta solo un par de años más tarde de su muerte y que su representación escultórica, confundida con "una aguerrida dama de mármol que representaba la libertad”, alcanzó lugares públicos pocas décadas más tarde 29 .

Volviendo a las cuatro canciones que sobreviven, es posible contemplar el uso político de la música durante este período en Lima (y otras áreas del Perú, como Arequipa ${ }^{30}$ ) en el teatro, los espacios públicos abiertos y el campo de batalla, la diversión popular y el salón ilustrado. El esfuerzo común de todas estas podría describirse como un intento por lograr la "adhesión voluntaria" de los ciudadanos al nuevo proyecto nacional, algo quizás más difícil dentro de la situación peruana. Un cronista contemporáneo rememora la música en la mañana misma de la batalla

probablemente en diciembre. Es, por lo tanto, en este período de aproximadamente cinco años que se puede fijar la creación de estas canciones patrióticas.

27 Es de hacer notar que probablemente fue el hecho fortuito de que su canción Somos libres se transformara en himno nacional el que conllevó que su obra se salvara de la desaparición. El propio músico no dudó en recordar en diversos momentos su situación como autor del Himno Nacional para solicitar reconocimiento en Lima.

28 Todas estas canciones, con excepción de la que hoy es el himno nacional peruano, pueden verse en el sitio IMSLP Petrucci Music Library: www.imslp.org (buscar por Alzedo).

29 La ciudad referida es Piura y la cita corresponde a un fragmento de la novela de Mario Vargas Llosa El héroe discreto, capítulo xviii. La estatua en cuestión fue regalada a la comunidad piurana por el presidente José Balta alrededor de 1870, y habría reemplazado una anterior y más modesta que habría sido la figura original de la heroína colombiana.

30 Ver, por ejemplo, González Ramírez 1995: 85-117. 
de Ayacucho con emoción y nos acerca al verdadero efecto de estas músicas: "En competencia unas con otras, habían venido durante las campañas trasladándonos en espíritu a nuestros hogares y pueblos; pero en la sublime expectación de esta mañana, el tumulto de sus golpes de armonía fue para nosotros licor de gloria y sentíamos que fundía el corazón de 6.000 hombres en uno solo ardiente y grande como la América"31.

El uso de canciones patrióticas desde fines del siglo XVIII es parte de un fenómeno mayor que incluye panfletos, periódicos y manifestaciones públicas como base para la comunicación de ideas a una audiencia mayor. El vivo ejemplo de La Marsellesa en Francia, o de La Carmañola (La carmagnole) -con sus múltiples contrafacta europeas y americanas $-{ }^{32}$, produjeron una proliferación de este tipo de canciones en suelo español y, por consiguiente, en territorio americano. Tadeo de Murguia, en un panfleto de 1809 citado por Begoña Lolo, ya señalaba que la música era "uno de los medios más eficaces para exaltar el patriotismo y el valor"33. Difícilmente imaginarían los literatos españoles que la masificación del uso de estas canciones en la guerra contra Napoleón terminaría incidiendo tan radicalmente en su masificación americana. Uno de los ejemplos más tempranos de canciones de este tipo lo encontramos en Venezuela y se trata de la Canción americana de 1797 , reeditada en $1811^{34}$.

Conocemos el caso de una canción patriótica española, en contra de Napoleón, que circuló en Lima durante la década de 1810 y cuya música se conserva. Se trata del "God Seivd de Kin" (sic.) impreso en Cádiz como parte de una Colección de Canciones Patrióticas hechas en demostración de la Lealtad Española y que, según señala el librillo, fue "cantada en el Teatro de Cádiz el día 28 de Abril de 1809". La versión americana, que se encuentra en la Biblioteca Nacional del Perú (MsMu5.9C), destaca principalmente por su orquestación para voces, dos flautas, dos clarinetes, dos clarines, dos violines, viola y bajo. La instrumentación implica una enorme flexibilidad melódica y ornamental para cada una de las partes instrumentales, generando una cacofonía sobre la melodía del actual himno nacional inglés y aprovechando los recursos para una mayor densidad sonora que el permitido por octavas o terceras paralelas, de uso más habitual. La principal relevancia de esta fuente, para este artículo al menos, es el modo en que Alzedo pudo recibir o entender la función de la canción patriótica, como una pieza que debía producir una impresión sobrecogedora en sus diversos elementos. De hecho, creemos que incluso la versión para piano que conserva su arreglo (previo a las transformaciones

31 Manuel Antonio López, Recuerdos Históricos de la Guerra de la Independencia, Lima, 1919, citado por Andragno-Walcker 2011:110.

$32 \mathrm{Al}$ respecto ver Bugliani 1999.

33 Lolo 2007: 236.

34 Bugliani (1999:13) apunta acertadamente que en la segunda versión de esta canción se hace eco de las acciones "por América" en pasado y no en presente, un cambio verbal relevante que alumbra en el cambio en el uso de estas canciones y su apropiación local. 
autorizadas de Rebagliatti) reconoce esta pretensión de "coloratura instrumental" en la canción nacional. ${ }^{35}$

Sin embargo, la transición entre "canción política" e "himno nacional" es una mucho más compleja que, sin duda, excede un tanto el horizonte de este trabajo. Aun así, es importante señalar que el Somos libres de Alzedo, actual canción nacional del Perú, tiene una conciencia estructural que apunta a que pudo haber sido compuesto desde su inicio con la idea de un himno, bajo una estructura particular que Alzedo defenderá hasta sus últimos días. ${ }^{36}$ Su principal uso, por lo tanto, era grupal y coral. Mariano Soldán en su Historia del Perú independiente recoge cómo, en el informe de una batalla a comienzos de septiembre de 1822, Rodil inspiró a sus soldados con "el ardor que le animaba, y entonando la canción patriótica, marcharon sobre la hacienda, resueltos todos a vencer o morir con honor" 37 . Frente a este uso profundamente emocional del himno, existía también su rol oficial, declarado en forma determinante desde el gobierno a un pueblo no del todo entusiasta. Un viajero en 1822 comentaba cómo en la plaza de toros, durante los espectáculos, era cantada por casi mil personas. Cuando Torre Tagle se instalaba en el palco oficial, junto a los funcionarios, "una banda de música comienza con la canción nacional, pero no se observa ninguna exteriorización de un entusiasmo nacional con esta aparición. Solo cuando las puertas dieron paso a los toros, es que la gente estalló en aplausos y gritos resonaron por el circo"38.

Esta narración se puede contrastar de manera clara con la de Brackenridge en Argentina, quien en 1818 visitó el Coliseo de Buenos Aires señalando: "Se cantó el Himno Nacional por toda la compañía teatral, acompañada por la orquesta, durante el cual es de rigor que todas las personas estén de pie; el canto fue seguido de aplausos atronadores"39. Esta dualidad entre formalidad oficialidad y espontaneidad popular de un sentimiento nacional es central para entender el rol de un objeto musical como el himno de Alzedo. Es probable que quede reflejado en el conocido detalle de que la melodía debía ser cantada por los niños en la plaza por decreto del mismo San Martín, una tradición ya arraigada en Buenos

35 Esta versión fue editada por primera vez en Lima por Niemeyer e Inghirami en mayo de 1864 (Raygada 1951, I: 106) y parece ser la única aprobada por el compositor antes de la reedición de Rebagliatti. Existe una copia en el periódico El Americano, editado en París, $\mathrm{N}^{\circ}$ 13, del 18 de junio de 1872 .

36 Alzedo entabló un debate durante la década de 1860 con Juan Eklund, músico sueco radicado en Lima por aquel entonces. Todo comenzó con un alegato por parte de Alzedo relativo a un arreglo de la canción nacional realizado por Eklund y publicado en Lima en El Comercio del 28 de mayo de 1864. Las respuestas se sucedieron (ver Raygada 1954, II: 52-57), llegando a violentos epítetos en las últimas publicaciones. Entre los elementos que Alzedo rechaza está la transformación de la estrofa a un tiempo más lento y lírico, el coro escrito a varias voces (debiendo ser unísono, en su opinión) y la rearmonización de su trabajo que, con toda razón, considera como "propiedad intelectual", un concepto relativamente nuevo para la época. Y aquí radica el mayor problema en la discusión: ¿Cómo podía ser esta canción nacional en iguales partes propiedad exclusiva de su autor y colectiva de la nación a un mismo tiempo? ¿De quién es, en último término, una canción nacional?

37 Soldán 1870: 35.

38 Farquhar 1825: 300.

39 Citado por Gesualdo 1961: 134. 
Aires en el estreno de la Marcha Patriótica de Blas Parera, que es el actual himno argentino, y proyectada luego también en Santiago de Chile durante el gobierno de O'Higgins ${ }^{40}$. La inocencia misma de los niños proclama la pureza del himno, pero reconoce la indoctrinación que este implica. La idea de un himno conllevaba, desde su génesis, la posibilidad de un estilo que fuera asumido como neutro, en la búsqueda de la homogeneidad nacional, un largo proceso no necesariamente colectivo que involucró de diversas maneras a la población americana y, puede argüirse, que lo sigue haciendo. Aquí, como ha planteado Isabel Cruz, podría tratarse de una transición entre la fiesta pública barroca y la incorporación de modelos foráneos, en particular captados por la prensa moderna europea, republicana y con marcada influencia francesa ${ }^{41}$.

\section{Somos libres}

Si bien se han escrito muchas líneas sobre el Himno Nacional del Perú ${ }^{42}$, cabe aquí hacer algunas relaciones en torno a los modelos de Alzedo y, también, a algunos de los aspectos musicales que aparecen como claves en el desarrollo de la pieza, que parece seguir un itinerario semejante al proceso libertador sanmartiniano (Argentina-Chile-Perú). En primer lugar, debe reconocerse el modelo del himno argentino, una melodía oficial encargada a un compositor profesional y que, además, es validada por el poder de un grupo de ciudadanos en el gobierno ${ }^{43}$. Esto es relevante, pues muchas de las canciones patrióticas que fueron utilizadas durante el periodo, y que no alcanzaron la condición de himno nacional, corresponden a aquellas de circulación pública en folletines o por transmisión oral, como posiblemente ocurrió con el que luego se convertiría en el Himno de Venezuela (1811), el más antiguo de la región, como hemos señalado.

Es interesante el modo en que Alzedo toma el modelo argentino, el que si bien sigue en buena parte su posible estructura original (sin la posterior introducción rossiniana), ${ }^{44}$ tiene una concreta y activa dimensión de acto revolucionario

40 En Argentina el estreno fue con un grupo de niños vestidos de modo "indiano" en las Fiestas Mayas de 1813. En Chile La Gazeta Ministerial del 21 de febrero publica el bando por el que se le pide a los niños de todas las escuelas cantar "las canciones patrióticas que se han preparado" en las plazas para el 12 de aquel mes. En el caso limeño, Torre Tagle firmó el bando $\mathrm{N}^{\circ} 1557$ del 13 de abril de 1822, que obligaba todos los domingos a las cuatro de la tarde a "los niños de todas las escuelas" a "cantar la marcha nacional del Perú, que por ahora se ha adoptado, cuidando los maestros de que lo ejecuten con el mayor decoro y propiedad".

41 Cruz de Amenábar 1995: 296.

42 A la fecha sigue siendo un referente insoslayable el libro de Carlos Raygada (1954).

43 Una referencia interesante a este respecto es el artículo de Susana Poch (1998).

44 Aunque habitualmente el himno argentino se analiza y entiende con esta introducción, debido a las copias tardías que sobreviven del himno, hay suficientes pruebas de que la misma fue introducida posteriormente. En su diatriba contra las introducciones, José Zapiola apunta en sus Recuerdos de treinta años: "La Marsellesa no tenía en su principio introducción; no la tiene la inglesa God save the King, a pesar de su pequeñez, ni la tenía en su origen la canción argentina, que después hemos visto preceder de una especie de introducción que, sin duda, es una imitación de alguna antigua misa de réquiem. La canción peruana, última de las que hemos nombrado, tampoco la tuvo al principio. Su autor, don Bernardo Alzedo, le puso introducción a su vuelta al Perú, el año 1864" (1872: 110). 
decretado oficialmente, con ecos que viajaron por una década por América del Sur antes de aterrizar en Lima. Aun así, la disposición musical que hace Alzedo parece mucho más radical y combativa. $\mathrm{Al}$ contrario del himno argentino, que trastoca la Marsellesa evitando la dirección ascendente en el fragmento melódico inicial, Alzedo asume la influencia francesa de forma bastante evidente, cuando en la estrofa peruana el solo canta: "de los libres, el grito sagrado", haciendo una referencia melódica a las primeras notas de la Marsellesa (ver ejemplo 1).

Ejemplo 1

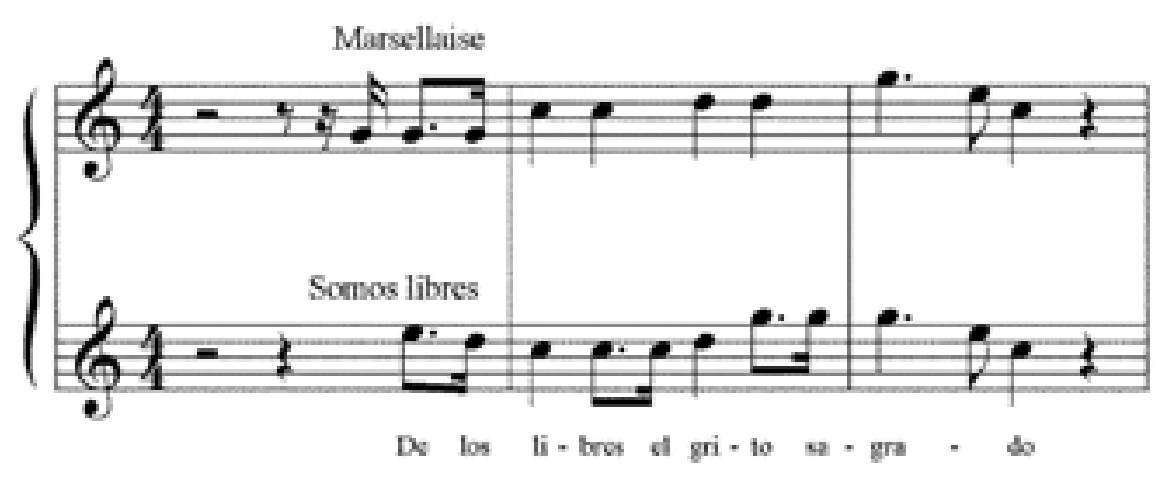

Esta relación intertextual, por medio de la voz que canta "el grito sagrado" en la obra de Alzedo, abre una brecha interesante ante la posibilidad de abarcar una colectividad mayor a la peruana. Si bien un himno nacional, como lo ha propuesto Benedict Anderson (1991: 145), representa un canto colectivo, simultáneo y espontáneo sobre algo que, de modo "mágico", todos parecemos conocer a la vez (volviéndonos "unísonos", una sola voz y comunidad), el diálogo que propone Alzedo amplía la proporción del acontecimiento. En cierto modo, su himno sería un canto revolucionario que asume un "grito sagrado" que es colectivo y amplio, cruzando de Europa a América. Alzedo entonces estaría tomando la antorcha de la revolución de este lado del Atlántico. En la perspectiva de una narración nacionalista histórica de doscientos años, Alzedo hizo lo que desde nuestra mirada actual nos parece lógico al cantar a la Independencia. No obstante, al situarnos en su momento histórico, podemos constatar que él tomó conscientemente una posición política clave que queda reflejada en esta y en las posteriores canciones.

\section{La Cora}

Este es un caso particularmente interesante de canción patriótica, pues existe una serie de diferencias entre esta y el resto de las canciones del mismo tipo de Alzedo en tiempos de la Independencia peruana. Mientras el Somos libres, La Chicha y la Despedida de las chilenas remiten a los eventos contemporáneos en forma directa, cada una a su modo, La Cora toma como subtexto una escena mítico-histórica, 
una fantasía con ribetes de teatro. En ella, el compositor construye una propuesta revolucionaria y nacional a partir de elementos que son, en gran medida e irónicamente, originados en una fantasía europea. La historia de los amantes Cora y Alonso, origen mítico de la canción de Alzedo, se construyó progresivamente a partir de su invención por Jean-Francois Marmontel en su libro Los Incas o la Destrucción del Perú, publicado en Francia en 1777 con gran éxito. Vertido en dos volúmenes, este trabajo tuvo una enorme influencia en la creación de un ideal de mujer indígena americana que es a la vez bella, sumisa, aunque independiente en sus ideas y exótica en su totalidad, una imagen duramente criticada posteriormente por Hector Berlioz en uno de sus Grotescos de la música ${ }^{45}$. Cora aparece descrita como la belleza y verdad natural en el marco de la tragedia de la conquista del Perú, establecida por Marmontel en un tono clásico similar al de la Eneida de Virgilio. El libro de Marmontel narra diversos hechos históricos, intercalados por una historia de amor que hila los sucesos, cuyos protagonistas son Alonso de Molina -personaje ficticio homónimo del escritor- y la princesa Cora, virgen del sol ${ }^{46}$. Alonso, caballero español, se enamora de la bella Cora, a quien ve en un festival sagrado, la conquista y posee en una noche, a un costado del Templo del Sol. Ella queda embarazada y es condenada a muerte, pero Alonso logra convencer a los líderes de la nación incaica de que la verdadera ley es la verdad natural, aquella que radica en el amor y la honestidad. Por esto, ambos son perdonados y celebrados como miembros de una nueva era. Las últimas líneas del monólogo de Alonso son, justamente, las siguientes: "Yo espero que pronto no tendremos sino un mismo altar; y a los pies de él, delante del ser supremo, será donde la religión habrá de santificar los votos de la naturaleza y del amor".

La fama del trabajo de Marmontel tuvo como uno de sus principales causantes esta historia de amor entretejida en el acontecer narrativo, por lo que la misma fue rápidamente convertida en libreto para teatro y ópera. Giuseppe Foppa realizó una primera versión para el compositor Francesco Bianchi, estrenada como Alonso $e$ Cora, en Viena en 1786. Giuseppe Bernardoti, por su parte, realizó otro libreto para Simon Mayr, en una versión del mismo nombre, aunque mucho más famosa en su tiempo, estrenada en La Scala de Milán en 1803. Ambas hacían uso de los coros, ballet y escenografía como recursos de exotismo y espectacularidad ${ }^{47}$. En ambas óperas, Alonso salva a Cora de la explosión de un volcán que destruiría el templo -el que fue representado con gran espectacularidad durante el estreno de la versión de Bianchi- y Cora es condenada, no por el amorío, sino por haber abandonado el lugar al que estaba consagrada eludiendo así el factor erótico de la historia. No son estas, sin embargo, las únicas versiones cantadas del mito: quizás la propuesta más famosa de todas fue la realizada por Etienne Méhul y titulada simplemente

45 Berlioz 1859: 68. El artículo original en francés se llama "Jaguarita - Les femmes sauvages" y es una crítica al ideal de mujer "exótica" americana contemplada en muchas óperas y obras de teatro francesas de la época.

46 El nombre empleado por Marmontel no es casual, por cuanto el origen griego del nombre (Korë) designa precisamente una doncella, o joven virgen.

47 Burwick 2009: 161-162. 
Cora, la que fue estrenada en París en 1791, en pleno periodo revolucionario y que tomaba la historia como eje para una crítica a la Iglesia Católica, representada en los fariseos sacerdotes incas de Marmontel. ${ }^{48}$ La versión de Simon Mayr y otra de Frederic Reynold estrenada en Londres en 1812 deben entenderse, por otra parte, a partir de la fobia generalizada durante las guerras napoleónicas al rapto y la violación de mujeres por parte de soldados extranjeros. La versión de Mayr fue reestrenada en 1815 como Cora, o la Vergine del Sole, siendo su rol protagónico cantado por el español Manuel García, tenor extraordinario que en la década de 1820 fue uno de los primeros en llevar la ópera a México ${ }^{49}$. Los distintos usos que se le dio a la historia en estas versiones esconden, en ocasiones, el origen de la intención de Marmontel. En el libro original, la crítica a España y la defensa de la condición natural idealizada del indígena son una constante, mientras que constituyen aspectos ligeramente más irrelevantes en las óperas. Ya su título lo señala claramente al referir el proceso histórico como "la destrucción del Perú".

Aunque no tenemos claro si alguna de estas óperas o libretos teatrales fueron estrenados en Perú a comienzos del siglo XIX, la canción de Alzedo apunta claramente a una circulación del mito, porque la letra no concluye la historia, sino que la da por entendida entre los oyentes tanto a nivel de narrativa como simbólico. Probablemente Alzedo haya tomado como inspiración una circulación común de la historia, ya familiarizada entre la gente. Aun así, es relevante señalar que la primera traducción del libro de Marmontel al español fue realizada justamente en 1822 y editada por Francisco de Cabello y Meza. El texto fue impreso por Masson en París y, podemos suponer que puede haber circulado en América dentro del mismo año, lo que podría explicar el origen de La Cora. Cabello, periodista y literato extremeño, en 1789 decidió radicarse en Lima, donde publicó el Diario de Lima, primer medio independiente en la capital virreinal. ${ }^{50}$

Por otra parte, es innegable que la canción de Alzedo debe haber sido parte de todo un movimiento de piezas teatrales y de teatro con música que apuntaban a factores locales o claramente nacionalistas y que eran relevantes para la construcción paulatina de una ciudadanía sudamericana. Como lo hemos señalado, el teatro, ya desde fines del siglo XVIII y en relación con todo un proceso escénico anterior, se estaba transformando también a escala regional en un factor de comunicación del pensamiento ilustrado y las normas e ideas de los nuevos tiempos. En este sentido, muchas de estas canciones posiblemente se presentaron en los escenarios, aunque es difícil adscribirlas a alguna tonadilla o drama particular. Quizás cumplieron roles independientes para amenizar en un programa de canciones o entre espectáculos escénicos. Pese a la proliferación de temáticas similares en el período, incluyendo referencias incaicas o precolombinas en general, la utilización en particular de este mito se instala como una novedad que necesariamente implica una dialéctica poderosa entre lo europeo y lo americano, una tendencia en varias de las canciones de Alzedo anteriormente referidas.

\footnotetext{
48 Abraham 1982: 390.

49 Radomski 2000: 110.

50 Más información sobre este tránsito de Cabello y Mesa en Martini (1998).
} 
La Cora, entonces, toma como punto de partida un mito europeo construido por necesidades retóricas y narrativas a partir de los ideales de la Ilustración hacia fines del siglo XVIII. Sin embargo, tanto en su tratamiento musical como literario, Alzedo transforma la canción y la invierte desde la otredad americana. Alonso ya no es el civilizado europeo que ilumina a los obtusos sacerdotes incas, sino un conquistador "acaso horroroso y terrible", que viene a invadir a la "divina y hermosa" Cora, virgen del sol. Alzedo, en su tratamiento de la canción, proporciona diversas luces de las consecuencias de esta unión: la palabra "amor", por ejemplo, la primera vez es acentuada directamente como sensible de Sol mayor, mientras que la segunda vez aparece contra un marcado La bemol, todo esto en la tonalidad de Do mayor. Hay en las últimas líneas, particularmente durante la repetición, una angustia que anuncia el sentido trágico de la historia, determinado por la idea de la "más cruda muerte". Si todas las óperas escritas en Europa sobre el mito concluyen en la alegría del perdón y la unión de los opuestos, Alzedo parece quedarse más bien en el anuncio de una posible tragedia, con ansiedad ante el juicio que le caerá encima a Cora. Sin embargo, también puede leerse esta pieza desde el conocimiento del libro original de Marmontel, en el que Alonso es asesinado por sus compatriotas, que lo ven como un traidor por su pacto con los Incas, mientras que Cora muere de pena junto al niño que lleva en el vientre, resultando la conquista simbólica en una tragedia para todas las partes, anulando incluso la esperanza del futuro.

Como colofón a esta historia, el personaje de Cora fue retomado por Antonio Ghislanzoni para la ópera Atahualpa de Carlo Enrico Pasta, quien residió varios años en Perú y la compuso durante su regreso a Italia, estrenándola el 23 de noviembre de 1875 en Génova. Allí Cora se enamora de otro español, Hernando de Soto, pero la historia conserva bastante de la trama original. Durante el último cuadro de la ópera, Cora proclama el odio al Dios de los cristianos, es condenada a muerte y, en su viaje al cadalso, profetiza un futuro libre para el Perú, con el fondo orquestal del Himno Nacional del mismo Alzedo, uniendo así dos capas simbólicas que el compositor ya había presagiado cincuenta años antes.

\section{La chicha}

Particularmente distinto es el caso de La chicha, canción que en su letra, melodía y acompañamiento, parece reconocer su vertiente popular. Entre las canciones de Alzedo del período emancipatorio, esta y la marcha patriótica Somos libres no solo tienen idéntica autoría de su texto y música, sino que presentan contenidos independentistas comunes. Además fueron las únicas que alcanzaron versiones impresas, aunque en distintos momentos, pero que en todo caso tuvieron amplia circulación y recepción. Al parecer ambas constituyen las dos caras de una misma moneda, por así decirlo, una especie de versiones a y b de una misma idea: celebrar el fin de la opresión española y el advenimiento de la independencia peruana, solo que están dirigidas a diversos segmentos sociales y en funciones también distintas. Por eso estimamos que surgieron en el mismo contexto y época: la llegada del Ejército Libertador liderado por San Martín en 1821, aunque los datos parecen 
apuntar a que La chicha habría antecedido por algunas semanas al himno nacional ${ }^{51}$, como una especie de preludio popular.

La marcha patriótica peruana comparte tópicos y contenidos textuales con la mayoría de los himnos sudamericanos en un lenguaje a la vez ilustrado y emancipador, dirigidos a un nuevo tipo de auditor, el ciudadano republicano que hace parte ahora del "concierto de naciones libres". Por su parte, La chicha parece recoger el localismo de la cultura popular de raíz indígena, en un ámbito de secular tradición e incluso apelando a proyecciones ceremoniales altamente significativas para la población americana, como el banquete ceremonial. Con posterioridad se ha considerado simplemente como una muestra de la importancia gastronómica de origen indígena, o al menos criollo, y a ese auditor parece dirigirse.

Resulta significativo comprobar que los creadores del texto y de la música, Alzedo y De la Torre Ugarte, también parecen representar a estos dos estratos sociales. Al parecer, y contrario a lo que se piensa comúnmente, el autor y el compositor no interactuaron presencialmente, ni menos fueron amigos personales. Por la época de composición de estas canciones Alzedo era un simple hermano terciario dominico, de procedencia mulata, que hacía vida conventual y De la Torre Ugarte un importante y acomodado funcionario, magistrado, hijo de un realista perteneciente a la nobleza peninsular ${ }^{52}$. Alzedo incluso señala en carta manuscrita que el autor del texto de los cantos Somos libres y La chicha fue "un caballero Yqueño”, para más adelante señalar “...llegando estas piezas a mis manos les puse música”. Esto indica que los versos probablemente le llegaron, quizás, en forma impresa.

El texto de La chicha llama a celebrar el fin de la opresión y el advenimiento de la independencia de una manera que el pueblo bien conoce: comiendo y bebiendo con alegría y placer. Si el himno conmina seriamente a relacionar la libertad con una nueva idea del progreso futuro, La chicha lo hace apelando con jolgorio a la tradición. Su núcleo semántico libertario parece contemplar esta doble dimensión, de pasado y futuro, y el elenco de manjares y bebidas tradicionales peruanas no deja de recordar la cuestión del origen incaico de la bebida.

Respecto de la vigencia de ambas piezas podemos constatar que una vez que la Marcha nacional del Perú, como original y provisoriamente fue convocada, se transformó en el Himno Nacional peruano definitivo, aseguró así su proyección en

51 Aunque San Martín había desembarcado en las costas peruanas en septiembre de 1820, no ingresa a Lima sino que a fines de junio (27) de 1821 y la Independencia es proclamada públicamente el 28 de julio. Entre el 7 y el 15 de agosto se hace pública la convocatoria para elegir una marcha patriótica, y este concurso se sanciona al mes siguiente entre el 18 y el 23. Creemos que La chicha pudo darse a conocer desde principios de julio, mientras que la marcha patriótica desde fines de septiembre.

52 Como patriota llegó a firmar el Acta de la Independencia en 1821, y murió como vocal de la Corte Superior de Justicia en Trujillo en 1831. En la Gaceta del Gobierno, N ${ }^{\circ}$ 45, miércoles 12 de diciembre 1821, figura su nombre entre los funcionarios de la presidencia que colaboran en dinero para la construcción de un navío. 
el tiempo ${ }^{53}$ y en la memoria peruana. En cambio La chicha, una vez que se disipó la emoción libertaria y los efluvios de su celebración prima, fue desapareciendo paulatinamente de la memoria colectiva y al cabo de treinta o cuarenta años más tarde ya solo era un recuerdo de aquella gesta. En tal sentido su texto es recogido a comienzos de la década de los sesenta en el Álbum de Ayacucho (1862), donde incluso es atribuida erróneamente a otro músico. ${ }^{54}$

Sin embargo, la popularidad de La chich a en su momento fue efectiva, al punto que el propio Alzedo en su frustrado viaje de regreso a Lima luego de varios años en Chile, inserta en un periódico local un anuncio en que, al ofrecer sus servicios musicales, recuerda al lector que aparte del himno nacional ("que hasta hoy nadie la ha mejorado", dice) fue autor también de La chicha. Con esto busca poner en evidencia que en este par de canciones él mismo veía su mejor carta de presentación, al menos en su ciudad natal. Si la crítica histórica puede hacernos dudar de la certeza de los términos anteriores por venir del propio Alzedo, más segura parece la validez de la opinión vertida por un autor limeño que en un artículo de prensa de 1862 a propósito del himno nacional y su autor, señala que "entre sus muchas sublimes inspiraciones, dio á luz la sublime canción del género jocoso titulada la 'Chicha' tan aplaudida hasta el colmo del frenesí” 55.

Pero no podría caber ya dudas del impacto de La chicha a nivel popular al leer el testimonio de un viajero europeo que, además de no tener ningún interés en promoverla, ni siquiera sabía de quién era tal canción, la que incluso considera de origen español. Este excepcional testimonio pertenece al inglés Robert Proctor, quien durante su viaje realizado al Perú en los años 1823 y 1824 relata que en una taberna rural a las afueras de un poblado serrano (Cocoto) un lugareño le invitó a pasar la noche en su rancho y antes de la comida, tomando la guitarra, había cantado una canción dedicada a la chicha. La anotación que el viajero hace del texto de la canción, aunque ligeramente modificada, permite identificar sin duda a la pieza de Alzedo y De la Torre Ugarte, ahora en un contexto claramente rural y ciertamente vehiculada por medio de la oralidad ${ }^{56}$.

Alzedo escoge para estos versos la forma de una canción que alterna estribillo y estrofa, en tono mayor y acentuación binaria, en la que destaca una efectiva célula rítmica característica (saltillo, par de corcheas, ver ejemplo 2).

53 Aunque con las vicisitudes, mudanzas y tensiones entre la prescripción oficial y la práctica tradicional que discute latamente Raygada (1954).

54 Herrera 1862:325. Recoge solamente el texto y señala equivocadamente que la música pertenece al músico Juan de Tena. En el prefacio se señala: "Nuestro objeto ha sido proporcionar a las personas, a quienes no hubiera sido fácil encontrarlos, sino hojeando los periódicos y papeles sueltos en que fueron publicados por primera vez, la comodidad por una parte, y por otra, la satisfacción íntima de que debe inundarse el corazón de todo amante de la libertad y de la gloria, al recorrer esas bellas pájinas de la historia de nuestra patria, escrita con la sangre y heroismo de nuestros padres".

55 El Comercio, Lima, viernes 17 de octubre de 1862.

56 Proctor 1825: 330-331. 
Ejemplo 2

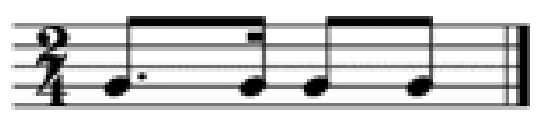

Así, esta pegajosa y efectiva canción circuló por los diversos espacios urbanos y rurales llevando su mensaje libertario asociado a la celebración popular, inseparable del banquete ritual americano con chicha y comida picante, y como parte del sistema simbólico que instaló la ideología independentista.

\section{La despedida de las chilenas al Ejército de San Martín Libertador del Perú}

Finalmente, La despedida de las chilenas es, quizás, la más elaborada de las canciones que Alzedo compuso en este período. Toma como su punto de inicio las primeras líneas de un largo poema en verso del mismo título que circuló, como pliego suelto, en Chile y Perú en compañía de otro llamado La despedida de las coquimbanas, de tono similar. Ambos se encuentran hoy digitalizados. ${ }^{57}$ Escrita como una pequeña escena con cambios rítmicos, armónicos y anímicos, pareciera haber sido creada pensando en el espacio íntimo del salón. Aunque habitualmente asociamos las canciones patrióticas con grandes manifestaciones urbanas colectivas, no fueron pocas aquellas escritas para el espacio íntimo de la discusión de la élite. Catalina Andragno-Walcker, por ejemplo, recoge aquella "música menos inmediata" en Colombia, como es el caso de La vencedora o La libertadora, ambas contradanzas de la década de $1820^{58}$. Aún así, esta canción es una pieza particularmente compleja, escrita no en forma binaria o ternaria, sino que transcompuesta, utilizando el total expresivo del texto en una relación entre el piano y la voz solista. ${ }^{59}$

Esta distinción o relación entre el piano y la voz articula buena parte de la emoción de la Despedida de las chilenas. El contraste se da entre la euforia popular y el entusiasmo por la partida del ejército libertador al Perú, en relación con la emoción contenida y a veces profundamente destemplada de una mujer (en representación de muchas) que ve partir, posiblemente, a su amado a la guerra y a un país lejano. Entre contraste, entre lo público y lo privado, anima la canción y genera un contrapunto radical con el espacio de algarabía y optimismo de las canciones patrióticas, aumentando aún más la expresividad ya contenida

57 Ambos están digitalizados y pueden consultarse en el sitio de Internet Archive, correspondiente a Chile Collection https://archive.org/details/despedidadelasco00coqu para el caso de las coquimbanas y para el documento referido a las chilenas, https://archive.org/details/despedidadelasch00chil

58 Andragno- Walker 2011:113-14.

59 Transcompuesta (durchkomponiert, through-composed) refiere al acto de no utilizar una misma música por estrofa, sino seguir el contenido literario o poético del texto con una propuesta musical continua y diversa. 
en La Cora, y el contraste con la exacerbación patriótica del himno Somos libres o La chicha.

El piano comienza con ritmo de saltillo y grandes acordes mayores (militares, patrióticos, fervorosos) que se desarman en figuraciones progresivas hacia la entrada de la voz. La letra comienza justamente con la frase "que terrible contraste”, que marca la tónica de toda la canción. Es interesante, por ejemplo, cómo el primer atisbo de duda se produce justamente en la armonía bajo la frase "la espedición [sic.] deseada" y luego el modo menor parece tomar el rol principal progresivamente en la canción. Cuando se llama enfáticamente a "marchad bravos guerreros", la armonía resuelve explícitamente a Fa menor, negando todo carácter militar. Las palabras finales "silencio, amor, marchad" quedan marcadas por un triple pianísimo, algunos calderones acumulados y el silencio de un saltillo de marcha que es apenas audible en el bajo.

\section{Consideraciones finales}

Las canciones patrióticas de José Bernardo Alzedo, enfrentadas desde la perspectiva de un creador único, reflejan un amplio espectro de perspectivas y posibilidades, no todas abarcables dentro de los mismos modelos ideológicos. La angustia de La despedida de las chilenas y el jolgorio de La chicha son, en su contraste, expresiones concretas de los muchos modos de aproximarse al ideal patriótico en Perú dentro de la década de 1820. Del mismo modo, las canciones no solo reflejan un espacio específico, como sería el teatro o las calles de Lima, sino que permiten abarcar, en su propio tiempo, una serie de formas de entusiasmo para distintas personas y situaciones. La canción patriótica es un género múltiple, complejo y sujeto a variadas transformaciones que, además, al convertirse en ícono de identidad o cohesión nacional, puede tener una vida aún más flexible con posterioridad. Las múltiples utilizaciones y variaciones constantes al Himno Nacional de Alzedo en nuestros días son, justamente, muestra de las muchas posibilidades de pertenencia y relectura de estas canciones creadas para generar identificación.

Por otra parte, Alzedo mismo se vio profundamente afectado por este período en su proceso creativo como autor. En la guerra contra España de 1866, Alzedo-de regreso en Lima luego de cuatro décadas chilenas- utilizó muchos de los recursos aprendidos para generar un nuevo repertorio de relevancia local, incluyendo la canción El Dos de Mayo, que tuvo cierta repercusión pública y que sobrevive también en la Biblioteca Nacional del Perú. Ciertamente también este aprendizaje se vertió en su trabajo como maestro de capilla de la catedral santiaguina entre 1846 y 1863 , proceso que queda reflejado particularmente en sus motetes y piezas breves con acompañamiento de órgano. Incluso, cabe pensar que algunas de estas últimas pudieran ser recicladas de antiguas canciones patrióticas. No sabemos cuánto es lo que se ha perdido, pero en aquellas canciones que sobreviven, la relación personal de un músico y un individuo como Alzedo con las ideas de la Independencia se destaca como un evento único en la música de América Latina durante las primeras décadas del siglo diecinueve. 


\section{BIBLIOGRAFÍA}

Abraham, Gerald

1982 The Age of Beethoven, 1790-1830. Oxford: Oxford University Press.

Alridge, A. Owen

1971 The Ibero-American Enlightenment. Urbana, Illinois: University of Illinois Press.

Álvarez Perca, Guillermo

1997 Historia de la orden dominicana en el Perú. Dos volúmenes. Lima.

Alzedo, José Bernardo

1869 Filosofía elemental de la música. Lima: Imprenta Liberal.

Anderson, Benedict

1991 Imagined Communities: Reflections on the Origin and Spread of Nationalism. Nueva York: Verso.

ANdragno-Walcker, Catalina

2011 "La identidad ecuatoriana a partir de la música y la poesía popular de las guerras de la independencia”, Araucaria, XIII/25, pp. 109-125.

BERLIOZ, Héctor

1859 Les grotesques de la Musique, París: Librerie Nouvelle.

Brown, Matthew y Gabriel Paquette

2011 "The Persistence of the Mutual Influence: Europe and Latin America in the 1820s", European History Quarterly, XLI/3 (julio), pp. 387-396.

Brown, Matthew y Gabriel Paquette (editores)

2013 Connections after Colonialism. Europe and Latin America in the 1820s. Tuscaloosa, Alabama: The University of Alabama Press.

Bugliani, Lía

1999 "La Carmañola americana (1797) entre la Carmagnole Francesa (1792) y el Canto de las Sabanas de Barinas (1817-1818)", Núcleo, Nº 16. Caracas, Distrito Federal, Venezuela: Universidad Central de Venezuela, pp. 3-26.

BurWick, Frederick

2009 Romantic Drama, Acting and Reacting. Cambridge: Cambridge University Press.

Chasteen, John

2008 Americanos: Latin America's Struggle for Independence. Oxford: Oxford University Press.

Coronel Zegarra, Félix Cipriano

1869 “D. José Bernardo Alzedo", en José Bernardo Alzedo. Filosofía elemental de la música. Lima: Imprenta Liberal, pp. iii-viii.

Cruz de Amenábar, Isabel

1995 La fiesta, metamorfosis de lo cotidiano. Santiago: Ediciones Universidad Católica de Chile.

Estenssoro, Juan Carlos.

1989 Música y sociedad coloniales: Lima 1680-1830. Lima: Colmillo Blanco.

EyzAgUirRe, Roberto

1973 Melchor Tapia and Music in the Lima Cathedral. Disertación para la obtención del grado de doctor (Ph D). Ann Arbor, Michigan: Universidad de Michigan. 


\section{FARQUHAR, GilberT}

1825 Narrative of a visit to Brazil, Chile, Peru, and the Sandwich islands, during the years 1821 and 1822. With miscellaneous remarks on the past and present state, and political prospects of those countries. Londres: C. Knight.

Gesualdo, Vicente

1961 Historia de la música en la Argentina. Volumen II. Primera edición. Buenos Aires: Editorial Beta SLR.

González Ramírez, Darío

1995 "El arte al servicio de la patria", Human Sciences Review. Escocia: St. Andrew's University. $\mathrm{N}^{\circ}$ 8, pp. 85-117.

\section{Guerrero, Carolina}

2006 Súbditos ciudadanos. Antinomias en la ilustración de la América andina. Caracas: Fundación de Estudios Latinoamericanos Rómulo Gallegos.

Herrera, José Hipólito

1862 El álbum de Ayacucho / Colección de los principales documentos / de la guerra / de la Independencia del Perú / y de los / cantos de victoria relativas a ella. Lima: Tipografía de Aurelio Alfaro.

LOLO, BEGONA

2007 "La música al servicio de la política en la guerra de la independencia", Cuadernos Dieciochistas, № 8, pp. 223-245.

LOAYZA, ÁLEX

2006 La política educativa del Estado peruano y las propuestas educativas de los colegios San Carlos y Nuestra Señora de Guadalupe. Lima, 1820-1857. Tesis para la obtención del grado de licenciado en historia. Lima: Universidad de San Marcos.

Mahoney, James

2010 Colonialism and Postcolonial Development: Spanish America in Comparative Perspective. Cambridge: Cambridge University Press.

Martini, Mónica

1998 Francisco Antonio Cabello y Mesa. Un publicista ilustrado de dos mundos (1786-1824). Buenos Aires: Instituto de Investigaciones sobre Identidad Cultural, Universidad del Salvador.

Morán, Luis y María Isabel AQuirre

2011 La educación popular en los tiempos de la independencia. Lima: Grupo Gráfico del Piero.

Paz Soldán, Mariano Felipe

1868-1874 Historia del Perú independiente. Lima: Imprenta y Esterotipia del Courrier de La Plata.

Poch, Susana

1998 "Himnos nacionales de América: poesía, Estado y poder en el siglo XIX", en Hugo Achugar (editor). La fundación de la palabra, letra y Nación en América Latina en el siglo XIX. Montevideo: Departamento de Publicaciones de la Universidad de la República, pp. 79-133.

Proctor, Robert

1825 Narrative of a Journey Across the Cordillera of the Andes, and of a Residence in Lima, and Other Parts of Peru, in the Years 1823 and 1824. Londres: A. Constable \& Co. 
RADOMSKI, JAMES

2000 Manuel García (1775-1832). Oxford: Oxford University Press.

Raygada, Carlos

1954 Historia crítica del Himno Nacional, Dos volúmenes. Lima: Juan Mejía Baca \& P.L. Villanueva Editores.

RONDÓN, Víctor

2013 "José Bernardo Alzedo: músico dominico y las ansias de ser", en Actas del Primer Congreso Internacional de Historia de la Orden de Predicadores en América. México, abril 2013 (en proceso de edición).

Rossi y Rubí, José

1791 "Idea general del Perú”, El Mercurio Peruano, Nº 1 (2 de enero de 1791).

Saldaña Retamar, Fray Reginaldo de la Cruz

1920 Los Dominicos en la Independencia Argentina. Buenos Aires: Imprenta Ceppi.

SAS, ANDrÉs

1971 La música en la Catedral de Lima durante el virreinato: Historia general. Dos volúmenes. Lima: Universidad Nacional Mayor de San Marcos, Casa de la Cultura del Perú.

STEvenson, Robert

1971 "Tribute to José Bernardo Alcedo (1788-1878)", Inter American Music Bulletin, $\mathrm{N}^{\mathrm{o}} 80$ (marzo-junio).Washington, D.C.: Organización de los Estados Americanos, pp. 1-22.

VÁsquez Castro, Marcel

2009 "Nación", en Javier Fernández Sebastián (editor). Diccionario político y social del mundo iberoamericano. La era de las revoluciones, 1750-1850. Madrid: Fundación Carolina, pp. 941-952.

ZAPIOLA, José

1872 Recuerdos de treinta años. Santiago de Chile: Imprenta de "El Independiente". 